\title{
LAS CARTAS Y “COPLAS” DE JORGE GUILLÉN
}

\author{
C. BRIAN MORRIS \\ Universidad de California, Los Ángeles
}

“¿Para quién se escribe una carta?” pregunta Jorge Guillén en una carta a Pedro Salinas con fecha del 8 de marzo de 1949, en la que repite las mismas palabras que su amigo había preguntado en El defensor (1948), en el extenso ensayo "Defensa de la carta misiva y de la correspondencia epistolar"1. Aislando la pregunta en un apartado y enmarcándola entre comillas, Guillén le confiere un carácter retórico y polémico que parece no preocuparle al dirigirse a su íntimo amigo, porque la hace precisamente para justificar el insulto que asesta a Luis Cernuda:

¿Qué tenemos que ver tú y yo con un marica? Como yo te escribo a ti y no a la posteridad - ¿para quién se escribe una carta?"- me permito expresarme en el lenguaje de la conversación ${ }^{2}$.

Poco probable es que Guillén hubiera escogido ese término de "marica" de haber sabido que su juicio sí llegaría a la posteridad. Al poeta

\footnotetext{
1 Salinas, El defensor, Madrid, Alianza, $2^{\text {a }}$ ed., 1984, p. 39.

2 Pedro Salinas/Jorge Guillén, Correspondencia (1923-1951), edición, introducción y notas de Andrés Soria Olmedo, Barcelona, Tusquets, 1992, p. 488. Citaré por esta edición, empleando la sigla $C O$.
} 
norteamericano Langston Hughes, la posteridad le parecía un bozal más bien que un aliciente. Cuando le enteró su amigo Carl Van Vechten en 1941 de que sus cartas iban a ser depositadas en un archivo especial en la Universidad de Yale, Hughes confesó sentirse cohibido. Vio primero el peligro de adoptar una postura artificial y un estilo alambicado, y luego la presión de la inhibición: después de comenzar a contar a Van Vechten una reyerta que presenció, se atajó, alegando que "la Raza [negra] vendría aquí a cortarme a navajazos si supiera que yo estaba transmitiendo tales noticias a la posteridad a través de la Biblioteca de Yale. Así que ahora ¿cómo te lo puedo contar?"3

Tanto Langston Hughes como Jorge Guillén señalan el abismo que media entre una comunicación privada y su conversión en documento público, entre confesarse voluntariamente ante un amigo y exponerse involuntariamente ante una masa anónima de lectores. En la soledad buscada de Miraflores de la Sierra, Vicente Aleixandre -para quien "La llegada del cartero es un acontecimiento" $4_{-}$habría comprendido la ansiedad del poeta canario Antonio Zerolo, separado de su querida isla y familia durante los siete años que ocupó la cátedra de lengua y literatura españolas en el Instituto de Bachillerato Jovellanos de Gijón:

¡Válgame Dios qué agonía!

¡Siempre esperando al cartero,

A ver si me trae nuevas

De los seres que más quiero ${ }^{5}$.

Esas "nuevas / De los seres que más quiero" no alegraron a Evelyn Waugh, quien reprendió a su esposa por haberle enviado "catálogos de datos familiares", aconsejándole que considerara una carta como "una conversación y no un diario"6. Aunque las expectativas varían según el lector, puede ser que

\footnotetext{
3 "You really should not tell me you are going to give all my letters to Yale because I will now become self-conscious and no doubt verge toward the grandiloquent..."; "but you know the Race would come out here and cut me if they knew I was relaying such news to posterity via the Yale library. So now how can I tell you?" (30 de octubre de 1941): Remember Me to Harlem. The Letters of Langston Hughes and Carl Van Vechten, 1925-1964, edición de Emily Bernard, Nueva York, Alfred A. Knopf, 2001, p. 193.

${ }^{4}$ Vicente Aleixandre, Epistolario, edición de José Luis Cano, Madrid, Alianza, 1986, p. 112.

5 "Cantares de un ausente", en Antonio Zerolo, Santa Cruz de Tenerife, Editorial Leoncio Rodríguez, 2001, p. 91.

6 "But that is no reason to make your letters as dull as your life. ... A letter should be a form of conversation; write as though you were talking to me. ... Be natural when you write. Don't send any more of these catalogues of family facts" (7 de enero de 1945); “Try to look on correspondence as a conversation not a diary" (9 de enero de 1945): The Letters of Evelyn Waugh, edición de Mark Amory, New Haven \& New York, Ticknor \& Fields, 1980, pp. 195, 197.
} 
todos busquemos algo en común: la "personalidad" que Carl Van Vechten admiró en las cartas de Langston Hughes7, o lo que Ramón Sijé denominó, en términos más ampulosos, el "pintoresquismo íntimo, la escenografía del misterioso teatro del alma"8. Por impresionantes que sean estas palabras, esa escenografía tiene que incluir lo alto y lo bajo, lo noble y lo mezquino, y, en el caso de Miguel Hernández, quejas, recriminaciones, súplicas, es decir, toda una veta elegíaca.

Si nos sentimos incómodos y desazonados ante la lamentación de Miguel Hernández por "este desconcierto y sorda vida, humilde y humillada" 9 , es porque llegamos a conocer al hombre después de conocer al escritor. No podemos dudar del valor de las cartas de cualquier creador, aun cuando nos remuerde la sensación culpable de que no tenemos el derecho de leer la correspondencia ajena. Cuando vencemos ese recelo, leemos cartas con cierta expectación optimista de que nos iluminen y complementen los textos, y de que los textos convaliden las cartas. Afanosos, seguimos pistas, cazamos datos y pormenores, como el génesis de un poema -por ejemplo, la visita de Lorca a Coney Island ${ }^{10_{-}}$, o la opinión de T. S. Eliot sobre el papel de la emoción en la poesía11, o el efecto de la involuntaria abstinencia sexual de Evelyn Waugh sobre su novela Brideshead Revisited ${ }^{12}$. Cuando ocurren inconsistencias -por ejemplo, entre la carta de Lorca a sus padres sobre su visita a Coney Island y el poema, "Paisaje de la multitud que vomita (Anochecer de Coney Island)", que fue generado por su visita- , nosotros como lectores tenemos que conciliar al hombre y al escritor, quienes se encuentran a veces en conflicto. A veces nos gusta el escritor más que el hombre, cuyas cartas pueden desengañarnos, hasta repugnarnos, con datos que preferiríamos no saber, como las observaciones

\footnotetext{
7 "Your letters are always very full of your personality and are always very welcome" (10 de febrero de 1941): Remember Me to Harlem, op.cit., p.184.

8 Citado en Miguel Hernández, Epistolario, edición de Agustín Sánchez Vidal, Madrid, Alianza, 1986, p. 26.

${ }_{9}^{9}$ Miguel Hernández, Epistolario, op.cit., p. 53.

10 Véase C. Brian Morris, "Fat Body, Thin Soul: Lorca's Landscape of Coney Island", en Robert Havard (ed.), Lorca: Poet and Playwright. Essays in Honour of José María Aguirre, Cardiff, University of Wales Press, 1992, pp. 49-70.

11 "Certainly I don't deny the importance of emotion. I often find it present to me when other people find only frigidity -or vice versa. One writes about the world one has experienced: and experience without emotion (of some kind) is almost a contradiction. I think there is an important distinction between the emotions which are in the experience which is one's material and the emotion in the writing -the two seem to me very different" (a John Gould Fletcher, 23 de septiembre de 1920): The Letters of T. S. Eliot Volume I 1898-1922, edición de Valerie Eliot., San Diego-New York-London, Harcourt Brace Jovanovich, 1988, pp. 409-410.

12 "Sexual repression is making mag.op. rather smutty" (a Laura Waugh, 12 de mayo de 1944): The Letters of Evelyn Waugh, op.cit., p. 184.
} 
antisemíticas de Eliot y Waugh13, la sensibilidad a flor de piel de Aleixandre, habitante de un mundillo de intrigas, preocupado para que se escriban reseñas favorables de su obra ${ }^{14}$.

Si las cartas proporcionan una dimensión humana a un escritor, también pueden desmitificarle. Raras veces encontramos un equilibrio perfecto entre un escritor según se manifiesta en sus cartas y un escritor según se expresa en sus obras: o aprendemos demasiado sobre el hombre -como en el caso de Eliot, Waugh y Aleixandre- o nos quedamos decepcionados por no saber más sobre el hombre -como en el caso de Guillén, cuyas cartas nos dicen mucho más sobre el escritor que sobre el individuo. En contraste con el descuido afectado de Waugh, las cartas de Guillén mantienen un nivel tan consistente de dignidad, decoro y elegancia, están tan exentas de mezquindades, nimiedades y confesiones, que leer la palabra "marica" no puede sino extrañarnos. Las cartas de Jorge Guillén nos ofrecen el caso raro de la confluencia perfectamente lisa de hombre y poeta. Sus cartas convalidan sus poesías, y éstas convalidan sus cartas, y dos amigos entrañables -Guillén y Salinas- se animan, se admiran, se comprenden, y comparten los mismos valores e ideales humanistas. La correspondencia entre estos dos amigos, editada con tanto esmero por Andrés Soria Olmedo, es un volumen que ofrece el caso raro del intercambio de cartas cuando generalmente tenemos la oportunidad de leer solamente las cartas recopiladas de un solo escritor. Si la amistad íntima, ya legendaria, entre Guillén y Salinas es un lugar común de la historia literaria, esta correspondencia da a ese lugar común carne y hueso, tan profunda es la compenetración que evidencian las cartas. Pocos críticos han comprendido la vocación y la aspiración de Guillén tan bien como Salinas, que ofrece en sus cartas definiciones y elogios tan merecidos como el que escribió el 2 de diciembre de 1938: “¡Feliz tú, que trabajas como vives, al par que vives, y cuyo ordinario es lo extraordinario de la poesía!" (CO, pp. 196-197).

Cuando Salinas le dijo a su amigo, en su carta del 11 de noviembre de 1950, que "mi sueño sería no hacer nada, más que escribir y leer" (CO, p. 546), hizo eco casi exacto de la aspiración que le había confesado Guillén un año antes, en su carta del 8 de octubre de 1949: "Mi ideal, de difícil realización, es ahora más que nunca, un sillón con tiempo para leer, escribir y dormir" (CO, p. 513). Veinte años antes, en la primera edición de Cántico (1928), ese sillón

\footnotetext{
13 "being Semites I suppose they will survive somehow" (a Ezra Pound, 30 de mayo de 1920): The Letters of T. S.Eliot, op.cit., p. 384; "They have a wall here where the Jews blub" (a Katherine Asquith, 23 de diciembre de 1935): The Letters of Evelyn Waugh, op.cit., p. 103.

14 Sirvan como ejemplos: (con motivo de la antología de J. M. Castellet) "Yo de hecho resulto tratado con injusticia, con ignorancia" (19 de julio de 1960); “De lo de Dámaso con Panero estaba yo enterado, por el mismo Dámaso. Este me dijo que Panero se enfadó y que él no contestó nada. No me dijo la frase de Blas de Otero" (21 de julio de 1953): Epistolario, op.cit., pp. 169, 112.
} 
apareció como accesorio imprescindible del ideal del poeta, quien lo pregona como "beato" en el título de una décima donde convierte en algo positivo, deseado, el hecho de que "No pasa / Nada":
¡Beato sillón! La casa
Corrobora su presencia
Con la vaga intermitencia
De su invocación en masa
A la memoria. No pasa
Nada. Los ojos no ven,
Saben. El mundo está bien
Hecho. El instante lo exalta
A marea, de tan alta,
De tan alta, sin vaivén ${ }^{15}$.

Las cartas de Guillén contienen otros datos, fascinantes para los aficionados a su obra, que confirman la vocación y la perseverancia del poeta: "El pájaro en la mano" tendrá "en total 102 poemillas, 900 versos exactamente", predice a su amigo el 16 de noviembre de 1937 (CO, p. 183); “(Pero Cántico tiene que seguir adelante...)", le promete el 20 de junio de 1940 (CO, p. 238); "Es curioso: yo, que soy -sí, señor- el autor de Cántico- y lo mantengo íntegro- , sólo siento la sensación de la Nada en contacto con la comedia social", le comenta con orgullo el 26 de febrero de 1948 (CO, p. 436). No debería extrañarnos que "la persona" a quien Guillén celebra en el poema "He aquí la persona", sea "De una pieza", que tenga "Íntegra un alma", y que su virtud más sublime es

$$
\begin{aligned}
& \text { Voluntad incesante } \\
& \text { Contra infierno, } \\
& \text { Todas las horas ante } \\
& \text { Cielo eterno. } \quad(C, \text { p. 373) }
\end{aligned}
$$

La única acción que el poeta le atribuye a esa persona ejemplar es diseñar la tilde con "primores de mano", es decir, esmerarse en el acto de escribir. A Guillén sin duda le habría complacido la restauración de la tilde a los letreros de diversas calles de Los Ángeles, California, en agosto de 20016; sin duda alguna le habrían entristecido las controversias que suscitó. No debería

15 Guillén, Cántico, primera edición completa, Buenos Aires, Editorial Sudamericana, 1950, p. 235. Citaré por esta edición, usando la sigla $C$.

16 Ver Santiago Pozo, "Some Street Signs Get a Little Squiggle of Linguistic Respect", Los Angeles Times, 21 de agosto de 2001, y Patti Morrison, "Waltzing the Tilde Back into Sign Language”, Los Angeles Times, 22 de agosto de 2001. 
sorprendernos que la palabra escribir aparezca tan a menudo en sus cartas, con variantes tan juguetonas como "hacer coplas": “Tengo más que nunca ganas de hacer coplas", le escribe a Salinas el 8 de octubre de 1941 (CO, p. 259), y, ocho años más tarde, observa: "Lo único en que no siento menos ganas es en esto de las dichosas coplas" (8 de octubre de 1949, CO, p. 514). Repetidamente en sus cartas a Salinas, Guillén insiste en su deseo irresistible de escribir, al que sucumbe, en una frase elegante y memorable, "por querencia ineludible": "Ponerse a escribir en verso por pura voluntad, no; pero sí por querencia ineludible" (17 de marzo de 1945, CO, p. 347). Dirá más crípticamente, seis años más tarde, que "No se escribe para... Se escribe porque..." (18 de marzo de 1951, CO, p. 562). "No ha habido día sin poema -sin borrador de poema-", cuenta a su amigo el 13 de septiembre de 1942, como confirmación de su querencia, "El caso es que nunca he escrito con más ilusión ni más ahinco" (CO, pp. 280, 281). Y añade, con una reserva que revela su amor a la aliteración y su fino humor punzante: "No vayas a figurarte que voy a ser el Villaespesa de Valladolid. Trabajo igualmente, con la misma lentitud" (CO, p. 281). En otra carta, de octubre de 1946, equipara el escribir con vivir, afirmando que "hay que volver al trabajo para vivir más: escribir, en estos casos, es la verdadera acción" (CO, p. 400). Por esa razón, le urge a Salinas: “¡Escribe, escribe! Que eso es lo más importante ahora" (9 de marzo de 1947, CO, p. 414).

Con la misma cautela que le llevó a negar que trabajaba como "el Villaespesa de Valladolid", Guillén sintió la necesidad de precisar que el acto de escribir conllevaba otro deseo igualmente imperioso: el de ver el verso que uno ha redactado "inscrito en una página, en una lámina concreta...., inclinado siempre a perderse en el aire" (28 de noviembre de 1944, CO, p. 338). "Componer un poema es realizar el poema", sigue el poeta, "llevarlo hasta la página impresa" (CO, p. 339). Hasta y hacia son preposiciones claves en la estética de Guillén. Si su vocación es la de escritor, y si la única trayectoria posible de sus versos es "hasta la página impresa", él como poeta tiene primero que ir desbrozando dudas e imprecisiones para ir "Hacia el nombre", según su poema espléndido (C, p. 292), a fin de emprender otro viaje mental "Hacia el poema". Mientras el verso de Juan Ruiz que emplea como epígrafe -"mi corazón de trovar non se quita"- pregona su "querencia ineludible" de escribir, "Hacia el poema" capta el funcionamiento de esa querencia -es decir, la inspiración- y el ideal, tanto ético como estético, del poeta:

Siento que un ritmo se me desenlaza

De este barullo en que sin meta vago,

Y entregándome todo al nuevo halago

Doy con la claridad de una terraza, 
Donde es mi guía quien ahora traza

Límpido el orden en que me deshago

Del murmullo y su duende, más aciago

Que el gran silencio bajo la amenaza.

Se me juntan a flor de tanto obseso

Mal soñar las palabras decididas

A iluminarse en vívido volumen.

El son me da un perfil y carne y hueso.

La forma se me vuelve salvavidas.

Hacia una luz mis penas se consumen. $\quad(C$, p. 263)

Guillén plantea alternativas muy claras en este soneto: explícitamente, entre el orden, tanto mental como vital, y el desorden; e implícitamente, entre la oscuridad y la claridad, la noche y el día. Con "la amenaza", el poeta resume todas las fuerzas que se interponen entre su mente y la claridad, con las que tiene que combatir: "este barullo", "el murmullo y su duende", "el silencio", "tanto obseso / Mal soñar" y "mis penas". Sin embargo, ir hacia el poema es ir "Hacia una luz", gran símbolo universal que aparece primero metafóricamente en "la claridad de una terraza", y luego en "las palabras decididas / A iluminarse en vívido volumen". Si las palabras, entonces, tienen el poder de desterrar las tinieblas, representan la salvación al recordarnos el Libro de Génesis. La conexión entre las palabras y la luz, la expone Guillén en otros poemas; en "Ariadna, Ariadna", soneto que sigue directamente a "Hacia el poema", afirma el poeta: "Por ti me esfuerzo, forma de ese mundo / Posible en la palabra que lo alumbre" (C, p. 265); y en "Junto a un balcón", el "rayo de solo, agudo y preciso, ya amante", que entra por la ventana, "Se detiene / sobre el lomo de algún volumen visiblemente", con el resultado de que "Se ilumina, / Inmensa, la paz" (C, p. 291).

Cuando Guillén concluye en "Hacia el poema" que "La forma se me vuelve salvavidas", convierte en metáfora la convicción que expresó a Salinas en octubre de 1946, de que "hay que volver al trabajo para vivir más" (CO, p. 400). $\mathrm{Al}$ encauzar esa necesidad vital en el molde exacto de un soneto, Guillén hace que el poema llegue a ser, entonces, su propia convalidación, el viaje y la llegada, la derrota del barullo y del murmullo a través de las palabras, que él celebra en poemas como "Los nombres" $(C$, p. 26) y "La palabra necesaria" $(C$, p. 253). Su fe -expresada en su carta a Salinas del 8 de marzo de 1949- de que "a la larga, siempre se es leído, sentido y entendido" (CO, p. 488)- hace que leer un poema suyo sea acompañar al poeta, convirtiendo nuestro acto de leer en "la 
esencial compañía" que significa tanto para él. Leer el poema es también entregarse a la "lectura, lectura fervorosa de los textos mismos" que, según contó a Salinas el 2 de noviembre de 1950 (CO, p. 543), fue parte esencial de las clases que impartió en el Colegio de México. Este énfasis que Guillén da a lectura pone de relieve su convicción de que el texto literario vive, vibra, solamente cuando se lee. "Muy bien que cada Garcilaso tenga su Herrera, bienvenido", comentó a su amigo el 27 de marzo de 1951; "pero lo que más importa es que tenga sus lectores, sin anotaciones" (CO, p. 567).

Guillén recurre de nuevo al subrayado para dar énfasis a tres palabras que forman parte de su elogio de la novela El desnudo impecable, de Salinas: “¡Qué gusto, qué placer en esta fusión de la suprema calidad literaria con el carácter deleitoso de la obra! Adoro la delicia en prosa y en verso. Delicia profunda, grave -iy con cuánta felicidad humana y poética!" (20 de junio de 1951, CO, p. 577). Dos años antes, Guillén le había comunicado a su amigo una reacción parecida a El defensor, en la que sus palabras "complacencia... entretenido, embelesado y como embobado entre tantas delicias" celebran la prosa elegante de Salinas con un entusiasmo igualmente elegante: "He leído y en gran parte releído tu Defensor con tan mansa complacencia y tan gustosamente despacio que, entretenido, embelesado y como embobado entre tantas delicias, se me ha ido el santo al cielo" (7 de mayo de 1949, CO, p. 496). En su elogio de El defensor, Guillén se presenta a sí mismo como el lector ideal al mismo tiempo que entronca la lectura más con la emoción que con la inteligencia. Encontró un alma gemela en Salinas, quien le había escrito en 1945, acerca del poema "Lectura", que "Tu poema sería ejemplo insigne de la idea de lectura, tal como la tengo" (28 de agosto de 1945, CO, p. 358). Y para estrechar aún más los lazos de amistad entre los dos, Salinas desarrollaría en un largo ensayo de El Defensor, "Defensa de la lectura", su concepción y práctica de esa actividad, que tiene mucho en común con la de Guillén, hasta el punto de evocar de nuevo el "beato sillón" de éste en una afirmación lírica y elegante:

Hay un momento de sin igual godeo para muchos de nosotros. Es cuando el cuerpo se asienta a placer, acogido sin impertinentes apretujos, holgadamente, por unos brazos de sillón, y una simple presión del dedo despierta el milagro precioso de la luz de su invisible sueño cristalino, para que a su calor florezca, o se abra, esa flor -centenares de pétalos- , la imperecedera, el libro ${ }^{17}$.

Difícil es suprimir la impresión de que el ensayo de Salinas es una glosa elaborada del poema "Lectura" de Guillén; hay que desbrozar mucha prosa

17 Salinas, El defensor, op.cit., p. 195. 
para espigar frases tan acertadas -y subrayadas por el mismo autor- como "espacio de lector" y "espacio de la lectura"18. Para ese espacio y esa acción, Guillén creó la metáfora acertada "los cielos de la mente", la que justifica e ilustra en "Lectura", poema donde no razona, ni narra un proceso, sino que exalta el efecto de la lectura sobre la mente. En once estrofas de cuatro versos, el poeta presenta en "Lectura" el complemento imprescindible de "Hacia el poema", y mantiene al mismo tiempo el ambiente amoroso y luminoso que es esencial a las dos actividades:

No está ya solo el cielo con la nube Que blandamente vaga,

Sin cesar transformándose a la zaga

De su propio querube,

5 Ese querube del capricho a punto

De aparecer en medio

Del día. ¿Qué? ¿No afrontará el asedio

-Tan suave- del conjunto?

Dura el conjunto. Suavemente sabe

10 Persistir imperioso.

¿Plenitud se merece este reposo?

Basta un hombre por clave.

Alrededor de un hombre que camina

Confiado, seguro,

15 La realidad no espera su futuro

Para ser más divina.

Insistencia visible de una mano

Que acaricia, que ama.

¡Los trigos! Es la mies en panorama

Bajo el viento de un llano.

18 Salinas, El defensor, op.cit., pp. 182, 190. 
Ama el viento. ¡Los chopos! Y una hoja Realzará el instante.

¿Conjunto? Lo será de veras ante

Quien sin ver lo recoja.

25 Un hombre lee. Todo le rodea

La página en lectura.

¡Íntegro estío bajo el sol! Madura

La paz. ¿Jamás pelea?

En la página el verso, de contorno

Resueltamente neto,

Se confía a la luz como un objeto

Con aire blanco en torno.

¡Oh bloque potencial! Así emergente

De blancura, de gracia,

35 Lleva los signos más humanos hacia

Los cielos de la mente.

Aun camina el lector, y ya abstraído,

¿Quién dirige su paso?

40

Los renglones -mirad, de Garcilaso-

Palpitan: son un nido.

¡Paseante por campo que él se labra,

Paseante por su centro,

Con amor avanzando ya por dentro

De un todo que es Palabra!

(C, pp. 186-187)

Con su entretejido de hendecasílabos y heptasílabos enlazados en rimas cruzadas, Guillén ha creado una melodía tan equilibrada, tan acompasada, que nos invita a compartir con su lectura la misma serenidad que, según su poema, conlleva toda lectura. Es una tranquilidad que domina el poema después de las dos primeras estrofas, donde los versos encabalgados y las preguntas captan, con cierta urgencia, el nerviosismo del poeta ante la amenaza planteada al conjunto por una nube caprichosa. "Dura el conjunto", declara Guillén al principio de la estrofa tercera (v. 9), repitiendo un artículo de fe al mismo 
tiempo que subraya el andamiaje conceptual y simbólico del poema, mantenido con "plenitud" (v. 11), "Alrededor" (v. 13), "Todo lo rodea" (v. 25), "Íntegro estío bajo el sol" (v. 27), "contorno neto" (v. 29), "aire blanco en torno" (v. 32), "nido" (v. 40), "centro" (v. 42) y "un todo que es Palabra" (v. 44). El poeta ya nos había preparado para el significado simbólico de "Íntegro estío bajo el sol" mediante la alegoría con la que inició su poema: la de la nube que aparece en el cielo del mediodía, que prepara el terreno tanto para "Los cielos de la mente" (v. 36), como para las alusiones también alegóricas a la naturaleza en "¡Los trigos!” (v. 19) y “¡Los chopos!” (v. 21) acariciados por el viento.

Quien da vida y propósito a esta alegoría lo indica Guillén en su verso explicatorio "Basta un hombre por clave" (v. 12): la clave es un hombre, cuyo anonimato le confiere un papel ejemplar y una función especial cuando el poeta le sitúa en el centro de un mundo anímico apacible y entero. "Un hombre lee" (v. 25), dice sencillamente el poeta; rodeado por "La página en lectura" (v. 26) y un "bloque potencial" (v. 33), es un hombre tan receptivo, tan enfrascado en el acto de leer, que "Lleva los signos más humanos hacia / Los cielos de la mente" (vs. 35-36). Autor de algunos de esos signos humanos es Garcilaso de la Vega, que sirve de guía y modelo al lector, quien, al leer, emprende un viaje de infinitas posibilidades dentro de lo que Salinas denominó el "espacio de lector".

El final apoteósico de "Lectura" se empalma con la dedicatoria final de Cántico, igualmente encomiástica, en la que Guillén exalta a Salinas como "ávido de compartir la vida como fuente, de consumar la plenitud del ser en la fiel plenitud de las palabras". Para Guillén, las palabras crean su propio universo, y el que camina dentro de él es un ser bienaventurado, privilegiado para pasear "Con amor". Si Guillén -el escritor- , cree fervorosamente que la Palabra, las palabras, crean un Todo, un universo compacto y coherente, nosotros -los lectores- vemos una faceta fundamental de ese Todo en la unión estrecha entre sus cartas y sus "coplas", donde él afirma una y otra vez su vocación, su imperiosa necesidad de crear, con la misma insistencia que llevó a Picasso en tantos cuadros a pintarse a sí mismo en su estudio. Pocos poetas han documentado tan cándidamente como Guillén la "querencia ineludible" de crear; pocas obras poéticas demuestran tan elegantemente como Cántico la necesidad de responder a la llamada de su vocación. 